\title{
Benzyl isothiocyanate inhibits inflammasome activation in $E$. coli LPS-stimulated BV2 cells
}

\author{
CHANG-MIN LEE ${ }^{1 *}$, DAE-SUNG LEE ${ }^{2 *}$, WON-KYO JUNG ${ }^{3 *}$, JONG SU YOO $^{2}$, MI-JIN YIM ${ }^{2}$, YUNG HYUN CHOI ${ }^{4}$, \\ SAEGWANG PARK ${ }^{5}$, SU-KIL SEO ${ }^{5}$, JUNG SIK CHOI ${ }^{6}$, YOUNG-MIN LEE ${ }^{6}$, WON SUN PARK ${ }^{7}$ and IL-WHAN CHOI ${ }^{5}$ \\ ${ }^{1}$ Department of Molecular Microbiology and Immunology, Warren Alpert School of Medicine, Providence, \\ RI 02912, USA; ${ }^{2}$ National Marine Biodiversity Institute of Korea, Seocheon; ${ }^{3}$ Department of Biomedical Engineering, \\ and Center for Marine-Integrated Biomedical Technology (BK21 Plus), Pukyong National University; ${ }^{4}$ Department of Biochemistry, \\ College of Oriental Medicine, Dongeui University; ${ }^{5}$ Department of Microbiology and Immunology, College of Medicine, \\ Inje University; ${ }^{6}$ Department of Internal Medicine, Busan Paik Hospital, College of Medicine, Inje University, Busan; \\ ${ }^{7}$ Department of Physiology, Kangwon National University School of Medicine, Chuncheon, Republic of Korea
}

Received February 10, 2016; Accepted June 28, 2016

DOI: $10.3892 / \mathrm{ijmm} .2016 .2667$

\begin{abstract}
Inflammasomes are multi-protein complexes that play a crucial role in innate immune responses. Benzyl isothiocyanate (BITC) is a naturally occurring compound found in cruciferous vegetables, and BITC exhibits potential as a chemopreventive agent. However, whether BITC exerts inflammasome-mediated regulatory effects on neuroinflammation is unknown. In this study, we examined the effects of BITC on inflammasome-mediated interleukin-1 $\beta$ (IL-1 $\beta$ ) production in E. coli lipopolysaccharide (LPS)-stimulated $\mathrm{BV} 2$ microglial cells. IL-1 $\beta$ production is tightly regulated at the post-translational level through the inflammasoume. We measured the levels of IL-1 $\beta$ produced from the LPS-exposed BV2 microglial cells using enzyme-linked immunosorbent assays (ELISAs). The BITC regulatory mechanisms in inflammasome-mediated cellular signaling pathways were examined by RT-PCR, western blot analysis and electrophoretic mobility shift assays. BITC inhibited the secretion of IL-1 $\beta$ induced by LPS in the BV2 microglial cells. BITC inhibited inflammasome activation and NLR family, pyrin domain containing 3 (NLRP3)-mediated caspase-1 activation, and
\end{abstract}

Correspondence to: Professor Won Sun Park, Department of Physiology, Kangwon National University School of Medicine, 1 Kangwondaehak-gil, Chuncheon-si, Gangwon-do, Chuncheon 24341, Republic of Korea

E-mail: parkws@kangwon.ac.kr

Professor Il-Whan Choi, Department of Microbiology and Immunology, College of Medicine Inje University, 75 Bokji-Ro, Busanjin-gu, Busan 47392, Republic of Korea

E-mail: cihima@inje.ac.kr

${ }^{*}$ Contributed equally

Key words: interleukin-1 $\beta$, inflammasome, $\mathrm{P} 2 \mathrm{X} 7$ receptor, benzyl isothiocyanate, nuclear factor- $\kappa \mathrm{B}$, mitochondrial reactive oxygen species decreased the levels of inflammasome activation pro-inflammatory mediators, including mitochondrial reactive oxygen species (ROS) and adenosine triphosphate (ATP) secretion in the LPS-stimulated BV2 microglial cells. Furthermore, we demonstrated that nuclear factor- $\kappa \mathrm{B}(\mathrm{NF}-\kappa \mathrm{B})$ activation induced by LPS was inhibited by BITC, which may contribute to the attenuated secretion of IL-1 $\beta$. These BITC-mediated inhibitory effects on IL-1 $\beta$ expression may thus regulate neuroinflammation through the inflammasome-mediated signaling pathway.

\section{Introduction}

Interleukin-1 $\beta$ (IL-1 $\beta$ ) is a pivotal pro-inflammatory cytokine that has been linked to the pathogenesis of a broad spectrum of acute and chronic inflammatory diseases (1). IL-1 $\beta$ is synthesized as a precursor in the cytosol in response to various stimuli. A low level of IL-1 $\beta$ in vivo can evoke various mediators, which induce an inflammatory response (2). IL-1 $\beta$ is considered an important pro-inflammatory cytokine in the brain and plays a critical role in the progression of neuroinflammation (3). Neuroinflammation is a well-known factor in the pathogenesis of neurodegenerative diseases, such as Alzheimer's disease (AD), Parkinson's disease (PD) and multiple sclerosis (MS) (4). IL-1 $\beta$ is produced by lipopolysaccharide (LPS)-stimulated BV2 microglia. LPS induces neuroinflammation by activating inflammatory cells, including astrocytes and microglial cells (5). In a previous study, it was shown that the systemic injection of LPS led to neuroinflammatory responses in the brain, which then led to amyloid- $\beta$ accumulation (6).

As regards IL- $1 \beta$ biological activity, mature IL- $1 \beta$ is regulated through cytosolic multi-protein complexes referred to as inflammasomes, such as the NLR family, pyrin domain containing 3 (NLRP3) inflammasome, which contains a nucleotide binding domain leucine-rich repeat with a pyrin-domain containing 3 sensor, an apoptosis-associated speck-like protein containing a caspase-recruitment domain (ASC) adaptor and a caspase- 1 enzyme $(7,8)$. For the secretion of IL- $1 \beta$, pro-IL-1 $\beta$ must be cleaved by activated caspase-1. Caspase- 1 is activated 
by an inflammasome assembly with NLRP3, ASC and procaspase-1. LPS must induce IL-1 $\beta$ for caspase-1 activation in response to adenosine triphosphate (ATP), which is a well-characterized danger-associated molecular pattern (DAMP) $(9,10)$. Extracellular ATP promotes NLRP3 inflammasome activation by stimulating purinergic receptor $\mathrm{P} 2 \mathrm{X}$ ligand-gated ion channel 7 (P2X7) (11,12). Pro-caspase-1 association with NLRP3 binds the adaptor molecule ASC, leading to pro-caspase- 1 activation, which, in turn, triggers pro-IL-1 $\beta$ processing to mature IL- $1 \beta$, in LPS- and ATP-stimulated cells.

Isothiocyanates are found abundantly in cruciferous or 'cabbage family' vegetables, such as garden cress, broccoli, cabbage, kale, cauliflower and radish, and have been used as diet components with potent chemopreventive and/or anticancer properties $(13,14)$. Certain isothiocyanates, such as sulforaphane (SFN), phenethyl isothiocyanate (PEITC), and benzyl isothiocyanate (BITC), are derived from glucosinolates in cruciferous vegetables (15). Among several isothiocyanates, BITC $\left(\mathrm{C}_{8} \mathrm{H}_{7} \mathrm{NS}\right)$ (Fig. 1A) is an effector molecule in many cruciferous vegetable defense systems with antioxidant, antitumor and anti-inflammatory activity (16-18). It has been indicated that BITC exhibits anti-inflammatory activities (18); however, to the best of our knowledge, no studies to date have examined the effects of BITC on neuroinflammation, and in particular, through inflammasome mediation. In the present study, we examined the inhibitory effects of BITC against IL-1 $\beta$-induced expression in LPS-stimulated BV2 microglial cells, as well as its effects on intracellular signaling pathways, specifically inflammasome components.

\section{Materials and methods}

Reagents. We purchased LPS, BITC, diphenyleneiodonium (DPI) and N-acetyl-L-cysteine (NAC) from Sigma Chemical Co. (St. Louis, MO, USA); YCG 063 was obtained from Millipore (Billerica, MA, USA). An antibody against nuclear factor- $\kappa \mathrm{B}(\mathrm{NF}-\kappa \mathrm{B})$ (cat. no. 14-6731) was obtained from eBioscience (San Diego, CA, USA). The antibody against NLRP3 (cat. no. AG-20B-0014) was purchased from AdipoGen (San Diego, CA, USA). An antibody against IL-1 $\beta$ (cat. no. AF-401-NA) was purchased from R\&D Systems (Minneapolis, MN, USA). An antibody against caspase-1 (cat. no. sc-514) was purchased from Santa Cruz Biotechnology, Inc. (Santa Cruz, CA, USA). The CellTiter-Glo ${ }^{\circledR}$ Luminescent assay was purchased from Promega (Madison, WI, USA).

Cell culture. The murine BV2 cell line, obtained from Professor Eun-Hye Joe (Ajou University School of Medicine, Suwon, Korea), was maintained in Dulbecco's modified Eagle's medium (DMEM) supplemented with $10 \%$ fetal bovine serum (FBS), $100 \mathrm{U} / \mathrm{ml}$ penicillin and $100 \mu \mathrm{g} / \mathrm{ml}$ streptomycin at $37^{\circ} \mathrm{C}$ in a humidified incubator with $5 \% \mathrm{CO}_{2}$. Confluent cultures were passed using trypsinization. For the experiments, the cells were washed twice with warm DMEM (without phenol red) and cultured in serum-free medium for $16 \mathrm{~h}$ prior to the treatments. In all the experiments, the cells were treated with various concentrations $(1,5$ and $10 \mu \mathrm{M})$ of BITC for various periods of time prior to stimulation with LPS $(1 \mu \mathrm{g} / \mathrm{ml})$ for the indicated periods of time.
Table I. Information on primers used in RT-PCR.

\begin{tabular}{lrrr}
\hline Genes & NCBI no. & Primer sequences (5'-3') & $\begin{array}{l}\text { Size } \\
(\mathrm{bp})\end{array}$ \\
\hline IL-1 $\beta$ & NM_008361 & F: CTCGTGCTGTCGGACCCATAT & 254 \\
& & R:TTGAAGACAAACCGC TTTTCCA &
\end{tabular}

NLRP3 NM_145827 F: CTGTGTGTGGGACTGAAGCAC 543 R:GCAGCCCTGCTGTTTCAGCAC

GAPDH NM_001289726 F: TTCACCACCATGGAGAAGGC 237 R:GGCATGGACTGTGGTCATGA

IL-1 $\beta$, interleukin-1 $\beta$; GAPDH, glyceraldehyde 3-phosphate dehydrogenase; $\mathrm{F}$, forward; $\mathrm{R}$, reverse.

Determination of cell viability. Cell viability was assessed using the Cell Counting kit-8 (CCK-8; Dojindo Laboratories, Kumamoto, Japan). Briefly, wells containing $2 \times 10^{5}$ cells $/ \mathrm{ml}$ were treated with BITC $(0,1,5,10,20$ and $30 \mu \mathrm{M})$. Following incubation for $24 \mathrm{~h}$, the cells were washed twice with phosphate-buffered saline (PBS). CCK- 8 was then added to each well followed by incubation at $37^{\circ} \mathrm{C}$ for $1 \mathrm{~h}$ followed by an analysis at $450 \mathrm{~nm}$ using a microplate reader (Model EL800; Bio-Tek Instruments, Winooski, VT, USA).

Reverse transcriptase-polymerase chain reaction (RT-PCR). Total RNA was isolated using TRIzol reagent (Invitrogen, Carlsbad, CA, USA). Total RNA $(1.0 \mu \mathrm{g})$ which was obtained from the cells was reverse transcribed using M-MLV reverse transcriptase (Promega) to produce cDNA. The RT-generated cDNA encoding the IL-1 $\beta$, NLRP3 and glyceraldehyde 3-phosphate dehydrogenase (GAPDH) genes was amplified using PCR and selective primers (Table I). Following amplification, portions of the PCR reactions were subjected to agarose gel electrophoresis.

Measurement of ATP levels. The total ATP content was measured using the CellTiter-Glo ${ }^{\circledR}$ Luminescence assay kit following the manufacturer's instructions. Briefly, the assay buffer and substrate were equilibrated to room temperature. The buffer was transferred and gently mixed with the substrate to obtain a homogeneous solution. Twenty microliters of the culture medium and $20 \mu \mathrm{l}$ of the assay reagent were added to each well (384-well plate), and the content was gently mixed under light protection on an orbital shaker. After $10 \mathrm{~min}$, the luminescence was measured using a Microplate Reader (SpectraMax L; Molecular Devices, Devon, UK) at $570 \mathrm{~nm}$.

Enzyme-linked immunosorbent assay (ELISA). The level of IL-1 $\beta$ expression was measured using an ELISA kit (R\&D Systems). The cells were treated with various concentrations of NAC, DPI and YCG 063 for $1 \mathrm{~h}$ prior to LPS stimulation $(1 \mu \mathrm{g} / \mathrm{ml})$. Following incubation for $24 \mathrm{~h}$, the culture supernatants were collected, and the IL-1 $\beta$ quantity was measured. The results of ELISA were quantified using an ELISA plate reader (Model EL800; Bio-Tek Instruments) at $450 \mathrm{~nm}$, which was corrected for absorbance at $540 \mathrm{~nm}$ in accordance with the manufacturer's instructions. 
Western blotanalysis. The cells were washed 3 times with PBS and lysed with lysis buffer (Mammalian Cell-PE LB; G-Biosciences, St. Louis, MO, USA). Equal quantities of protein were separated on $10 \%$ sodium dodecyl sulfate (SDS)-polyacrylamide minigels and transferred onto nitrocellulose membranes. Following incubation with the appropriate primary antibody (IL-1 $\beta$, NLRP3, caspase- 1 and NF- $\mathrm{\kappa B}$ ), the membranes were incubated for $1 \mathrm{~h}$ at room temperature with a secondary antibody [goat antirabbit IgG (cat. no. 31460; Pierce, Rockford, IL, USA) goat anti-mouse IgG (cat. no. sc-2031; Santa Cruz Biotechnology, Inc.)] conjugated to horseradish peroxidase. Following 3 washes in Tris-buffered saline Tween-20 (TBST), the immunoreactive bands were visualized using the ECL detection system.

Electrophoretic mobility shift assay (EMSA). Nuclear extract was prepared using the NE-PER nuclear extraction reagent (Pierce). An oligonucleotide containing the immunoglobulin $\kappa$-chain binding site $\left(\kappa \mathrm{B}, 5^{\prime}\right.$-GATCTCAGAGGGGACTTT CCGAGAGA-3') was synthesized as a probe for the gel retardation assay. A non-radioactive method in which the $3^{\prime}$ end of the probe was labeled with biotin was used (Pierce). The binding reactions contained $5 \mu \mathrm{g}$ of nuclear extract protein, buffer (10 mM Tris, $\mathrm{pH} 7.5,50 \mathrm{mM} \mathrm{KCl}, 5 \mathrm{mM} \mathrm{MgCl}_{2}$, $1 \mathrm{mM}$ dithiothreitol, $0.05 \%$ Nonidet P-40, and $2.5 \%$ glycerol), $50 \mathrm{ng}$ of poly (dI-dC) and $20 \mathrm{fM}$ of the biotin-labeled DNA. The reactions were incubated for $20 \mathrm{~min}$ at room temperature in a final volume of $20 \mu \mathrm{l}$. The competition reactions were performed by the addition of a 100 -fold excess of unlabeled $\kappa \mathrm{B}$ to the reaction mixture. The mixture was then separated using electrophoresis on a $5 \%$ polyacrylamide gel in $0.5 \mathrm{X}$ Trisborate buffer and transferred to nylon membranes. The biotin-labeled DNA was detected using a LightShift chemiluminescent EMSA kit (Pierce).

Statistical analysis. Data values represent the means \pm standard deviation (SD). To analyze the data produced from the experiments with 2 independent variables, one-way analysis of variance (ANOVA) was performed using GraphPad Prism software (GraphPad Software, La Jolla, CA, USA). Values of $p<0.05, p<0.01$ and $p<0.001$ were considered to indicate statistically significant differences.

\section{Results}

Effects of BITC on BV2 microglial cell viability. Initially, we examined the viability of the BV2 microglial cells treated with $\operatorname{BITC}(1,5,10,20$ and $30 \mu \mathrm{M})$ by CCK- 8 assay. Treatment of the BV2 microglial cells with up to $10 \mu \mathrm{M}$ BITC did not produce any cytotoxic effects, whereas cell viability was significantly decreased by 80 and $82 \%$ following treatment with 20 and $30 \mu \mathrm{M}$ BITC, respectively (Fig. 1B). Based on these results, BITC at concentrations of 1,5 and $10 \mu \mathrm{M}$ was used in the subsequent experiments.

Effects of BITC on IL-1 $\beta$ expression in LPS-stimulated BV2 microglial cells. The IL-1 $\beta$ expression levels increased considerably following the stimulation of BV2 microglial cells with LPS (Fig. 2). The inhibitory effects of BITC on IL- $1 \beta$ mRNA and protein expression were determined using RT-PCR and ELISA, respectively. The IL-1 $\beta$ mRNA levels were markedly<smiles>S=C=NCc1ccccc1</smiles>

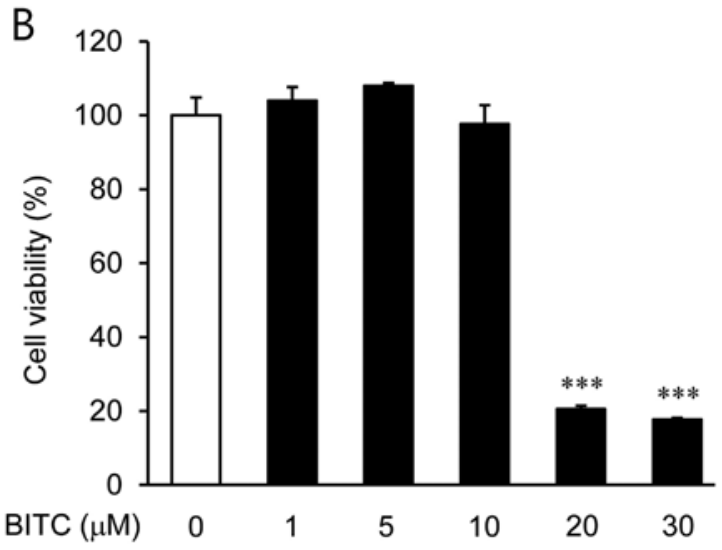

Figure 1. Chemical structure of benzyl isothiocyanate (BITC) and the effect of BITC on BV2 microglial cell viability. (A) Chemical structure of BITC. (B) The cells were treated with various concentrations $(1-30 \mu \mathrm{M})$ of BITC for 24 h. Cell viability was assessed using the cell counting kit-8 (CCK-8) assay, and the results are expressed as the percentage of surviving cells relative to the untreated cells. Each value indicates the mean \pm SD and is representative of results obtained from 3 independent experiments. ${ }^{* * *} \mathrm{p}<0.001$ vs. untreated cells.

upregulated after $3 \mathrm{~h}$ of LPS $(1 \mu \mathrm{g} / \mathrm{ml})$ stimulation, and BITC significantly decreased the IL- $1 \beta$ mRNA expression levels in the LPS-stimulated BV2 microglial cells in a concentrationdependent manner (Fig. 2A). To evaluate the effects of BITC on IL-1 $\beta$ protein expression in the LPS-stimulated BV2 microglial cells, the cells were treated with BITC $(1,5$ and $10 \mu \mathrm{M})$ for $1 \mathrm{~h}$ prior to LPS stimulation for $48 \mathrm{~h}$. Treatment with BITC suppressed the LPS-induced increase in IL-1 $\beta$ protein expression in a concentration-dependent manner (Fig. 2B). The results of ELISA revealed that the reduction in IL- $1 \beta$ protein levels correlated with a reduction i the corresponding mRNA levels.

Effects of BITC on NLRP3 and caspase-1 activation in LPS-stimulated BV2 microglial cells. To determine whether BITC affects NLRP3 and caspase-1 activation, the BV2 microglial cells were stimulated with LPS in the presence or absence of BITC. LPS significantly increased NLRP3 mRNA expression (Fig. 3A). However, treatment with BITC attenuated the increase in NLRP3 mRNA expression. To evaluate the effects of BITC on NALP3 and caspase-1 protein expression in the LPS-stimulated BV2 microglial cells, we pre-treated the cells with BITC $(1,5$ and $10 \mu \mathrm{M})$ prior to stimulation with LPS. Treatment with BITC suppressed the LPS-induced production of NLRP3 and caspase-1 (the subunit p10) activation in a concentration-dependent manner (Fig. 3B).

Effects of BITC on ATP levels in LPS-stimulated BV2 microglial cells. To quantify the total extracellular ATP levels, the BV2 microglial cells were stimulated with LPS in the presence or absence of BITC. LPS significantly increased the ATP levels (Fig. 4). To examine the effects of BITC on the ATP levels in LPS-stimulated BV2 microglial cells, we pre-treated the cells with BITC (1, 5 and $10 \mu \mathrm{M})$ prior to stimulation with 


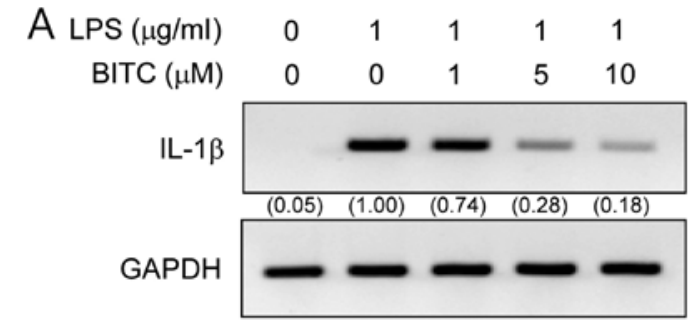

B

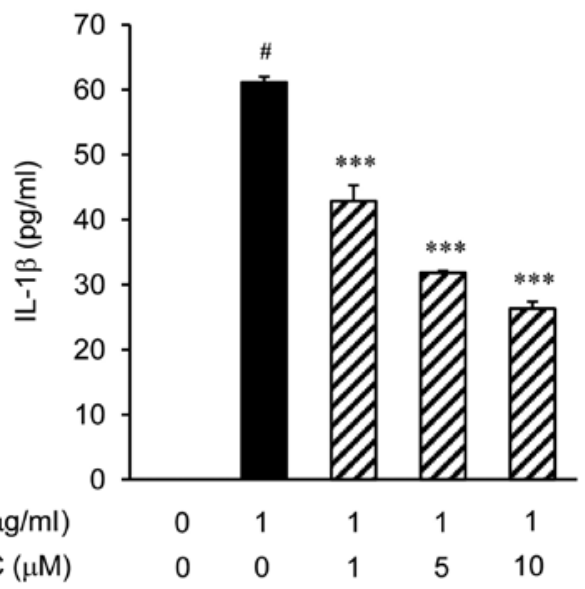

Figure 2. Effect of benzyl isothiocyanate (BITC) on intereukin-1 $\beta$ (IL-1 $\beta$ ) production by lipopolysaccharide (LPS)-stimulated BV2 microglial cells. The cells were seeded at $2 \times 10^{5}$ cells $/ \mathrm{ml}$ and incubated with various concentrations $(1,5$ and $10 \mu \mathrm{M}$ ) of BITC for $1 \mathrm{~h}$ prior to LPS stimulation (1 $\mu \mathrm{g} / \mathrm{ml})$ (A) Following stimulation with LPS for $3 \mathrm{~h}$, the IL-1 $\beta$ mRNA expression level was determined by RT-PCR. GAPDH was used as an internal control for RT-PCR. (B) Following incubation for $48 \mathrm{~h}$, the culture supernatant was collected, and the quantity of IL- $1 \beta$ was measured by ELISA. Each value indicates the mean \pm SD and is representative of results obtained from 3 independent experiments. ${ }^{*} \mathrm{p}<0.05$ vs. control group (no treatment); ${ }^{* * *} \mathrm{p}<0.001$ vs. LPS-stimulated group.

LPS. Treatment with BITC prevented the LPS-induced increase in ATP levels.

Involvement of mitochondrial ROS in NLRP3 and caspase-1 activation. We examined whether the LPS-induced IL-1 $\beta$ production is associated with ROS generation (Fig. 5). First, the BV2 microglial cells were stimulated with LPS for $24 \mathrm{~h}$ in the presence or absence of ROS inhibitors, such as the ROS scavenger, NAC ( 2 or $5 \mathrm{mM}$ ), the NADPH oxidase inhibitor, DPI ( 0.1 or $0.2 \mu \mathrm{M})$, and the mitochondrial ROS inhibitor, YCG 063 (10 or $20 \mu \mathrm{M})$ (Fig. 5A). YCG 063 significantly inhibited the LPS-induced production of IL-1 $\beta$. However, IL-1 $\beta$ expression was not altered in the cells pre-treated with NAC and DPI. To further determine the involvement of mitochondrial ROS in the inflammasome pathway, we analyzed inflammasome activation in the BV2 microglial cells. The immunoblot data showed that treatment with YCG 063 suppressed inflammasome activation, including NLRP3 and the active form of caspase-1 (Fig. 5B).

Effects of BITC on NF- $\kappa B$ activation in LPS-stimulated BV2 microglial cells. The production of IL-1 $\beta$ is regulated by the transcription factor, NF- $\kappa \mathrm{B}$. Furthermore, NF- $\kappa \mathrm{B}$ plays a critical role in priming the NLRP3 inflammasome (19). Therefore, to elucidate the mechanisms through which BITC affects IL- $1 \beta$ expression, we examined the effects of BITC on NF- $\kappa$ B activation. We examined the effects of BITC on LPS-induced

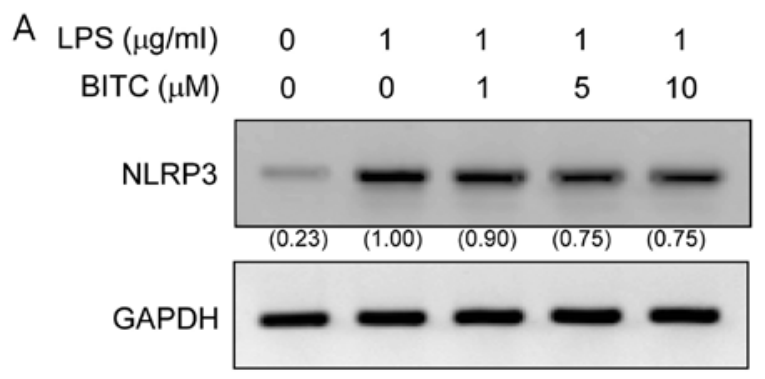

$\begin{array}{rllllc}\text { B LPS }(\mu \mathrm{g} / \mathrm{ml}) & 0 & 1 & 1 & 1 & 1 \\ \operatorname{BITC~}(\mu \mathrm{M}) & 0 & 0 & 1 & 5 & 10\end{array}$

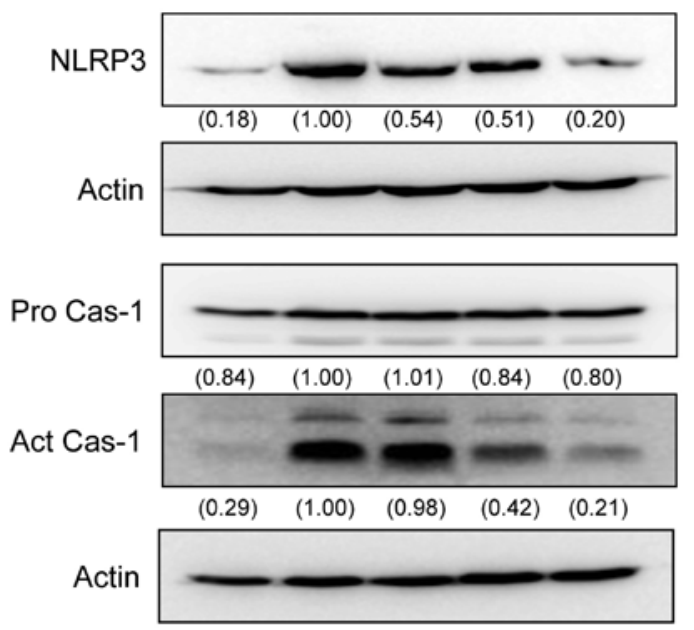

Figure 3. Effects of benzyl isothiocyanate (BITC) on NLRP3 and caspase-1 activation in lipopolysaccharide (LPS)-stimulated BV2 microglial cells. The cells were seeded at $2 \times 10^{5}$ cells $/ \mathrm{ml}$ and incubated with various concentrations $(1,5$, and $10 \mu \mathrm{M})$ of BITC for $1 \mathrm{~h}$ prior to LPS stimulation $(1 \mu \mathrm{g} / \mathrm{ml})$. (A) Following stimulation with LPS for $3 \mathrm{~h}$, the NLRP 3 mRNA expression levels were determined by RT-PCR. GAPDH was used as an internal control for RT-PCR. (B) Following stimulation with LPS for $24 \mathrm{~h}$, the cell lysates were resolved on sodium dodecyl sulfate (SDS)-polyacrylamide gels, transferred onto nitrocellulose membranes, and probed using antibodies against NLRP3 and caspase-1. Actin was used as an internal control for western blot analysis. Pro Cas-1, procaspase-1; Act Cas-1, active caspase-1.

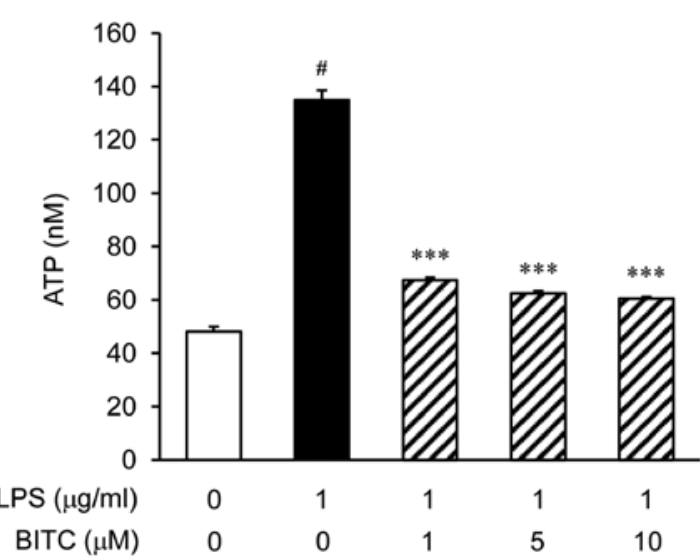

Figure 4. Effects of benzyl isothiocyanate (BITC) on adenosine triphosphate (ATP) levels in lipopolysaccharide (LPS)-stimulated BV2 microglial cells. The cells were seeded at $2 \times 10^{5}$ cells $/ \mathrm{ml}$ and incubated with various concentrations $(1,5$ and $10 \mu \mathrm{M})$ of BITC for $1 \mathrm{~h}$ prior to LPS stimulation $(1 \mu \mathrm{g} / \mathrm{ml})$ for $5 \mathrm{~min}$. The cell culture supernatant was analyzed for ATP secretion. ATP levels in the medium were detected using a luminescence-based assay in accordance with the manufacturer's instructions. Each value indicates the mean $\pm \mathrm{SD}$ and is representative of results obtained from 3 independent experiments. ${ }^{\#} \mathrm{p}<0.05 \mathrm{vs}$. control group (no treatment); ${ }^{* * * *} \mathrm{p}<0.001$ vs. LPS-stimulated group. 
A

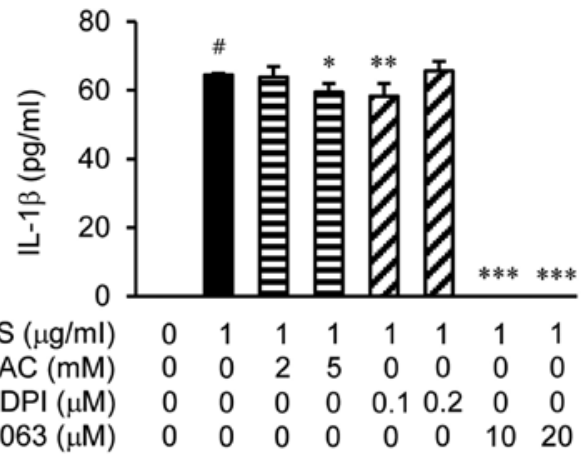

B

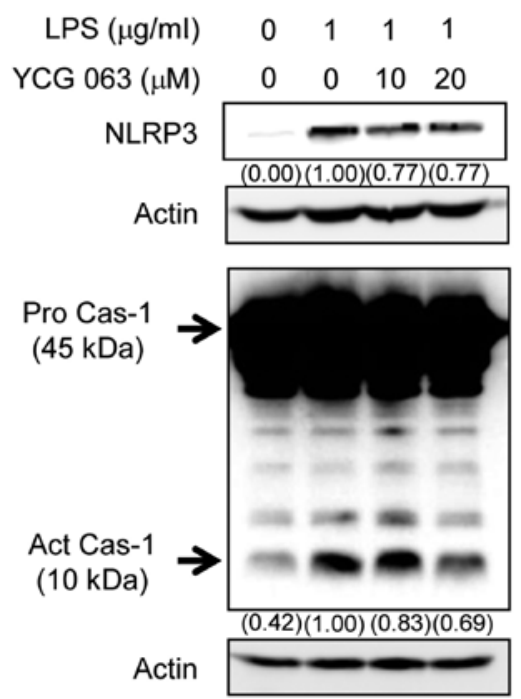

Figure 5. Involvement of mitochondrial reactive oxygen species (ROS) in the activation of NLRP3 and caspase-1. (A) Cells were seeded at $2 \times 10^{5}$ cells $/ \mathrm{ml}$ and incubated with the indicated concentrations of N-Acetyl-1-cysteine (NAC), diphenyleneiodonium (DPI) and YCG 063 for $1 \mathrm{~h}$ prior to lipopolysaccharide (LPS) stimulation $(1 \mu \mathrm{g} / \mathrm{ml})$. Following incubation for $24 \mathrm{~h}$, the culture thye supernatant was collected, and the IL-1 $\beta$ quantity was measured by ELISA. Each value indicates the mean $\pm \mathrm{SD}$ and is representative of results obtained from 3 independent experiments. ${ }^{\#} \mathrm{p}<0.05$ vs. control group (no treatment); ${ }^{*} \mathrm{p}<0.05,{ }^{* *} \mathrm{p}<0.01$ and ${ }^{* * * *} \mathrm{p}<0.001$ vs. LPS-stimulated group. (B) Following stimulation with LPS for $24 \mathrm{~h}$, the cell lysates were resolved on sodium dodecyl sulfate (SDS)-polyacrylamide gels, transferred onto nitrocellulose membranes, and probed using antibodies against NLRP3 and caspase-1. Actin was used as an internal control for western blot analysis. Pro Cas-1, procaspase-1; Act Cas-1, active caspase-1.

$\mathrm{NF}-\mathrm{\kappa B}$ p65 nuclear translocation as NF- $\kappa \mathrm{B}$ translocation to the nucleus is required for NF- $\mathrm{kB}$-dependent transcription following LPS stimulation. The nuclear localization of NF-кB p65 was examined by western blot analysis. The results revealed that stimulation of the BV2 microglial cells LPS strongly induced

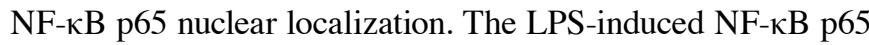
translocation was abolished by pre-treatment of the cells with BITC (Fig. 6A). We then examined the effects of BITC on the DNA-binding activity of NF- $\mathrm{KB}$ by EMSA (Fig. 6B); stimulation with LPS significantly increased the DNA-binding activity of NF- $\mathrm{KB}$, whereas pre-treatment wiht BITC reduced the LPS-induced NF- $\kappa B$ DNA-binding activity.

\section{Discussion}

Neuroinflammation may be a common characteristic of various neurological and neurodegenerative disorders through release

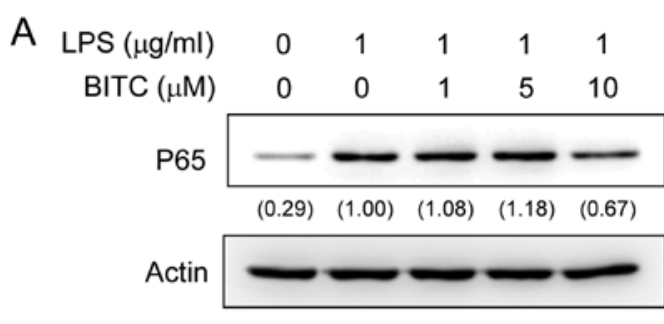

B

$\begin{array}{rllllll}\text { LPS }(\mu \mathrm{g} / \mathrm{ml}) & 0 & 1 & 1 & 1 & 1 & 1 \\ \mathrm{BITC}(\mu \mathrm{M}) & 0 & 0 & 1 & 5 & 10 & 0 \\ \text { Cold-кB } & - & - & - & - & - & +\end{array}$

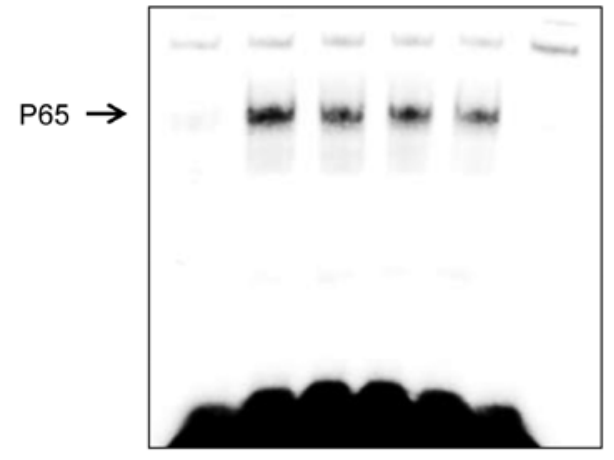

Figure 6. Effect of benzyl isothiocyanate (BITC) on the nuclear factor- $\mathrm{kB}$ $(\mathrm{NF}-\mathrm{\kappa B})$ translocation and binding to lipopolysaccharide (LPS)-stimulated BV2 microglial cell nuclei. The cells were treated with $\operatorname{BITC}(1,5$ and $10 \mu \mathrm{M})$ for $1 \mathrm{~h}$ and then stimulated with LPS for $2 \mathrm{~h}$. (A) Nuclear extracts were prepared as described in the Materials and methods and NF- $\mathrm{kB}$ translocation was evaluated by western blot analysis. (B) Nuclear protein extracts were prepared and analyzed for NF- $\mathrm{\kappa B}$ DNA binding activity using an electrophoretic mobility

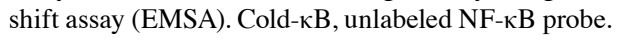

of proinflammatory cytokines and chemokines (20). A recent study demonstrated that inflammasome-mediated inflammation is involved in infectious diseases affecting the central nervous system (CNS) (21). In this respect, the regulation of inflammasome-mediated inflammatory pathways involved in infectious diseases affecting the CNS has gained attention. In this study, we investigated the inhibitory effects of BITC on IL-1 $\beta$ production in E. coli LPS-stimulated BV2 microglia. Additionally, we explored the several mechanisms involved in the inhibitory effects of BITC, specifically inflammasomeassociated pathways.

Microglia are the resident marcrophage cells and are widely distributed in the brain. In response to brain neuroinflammatory stimuli, activated microglia can overproduce pro-inflammatory and/or neurotoxic factors, including pro-inflammatory cytokines [IL-1, IL-6 and tumor necrosis factor- $\alpha$ (TNF- $\alpha$ )], nitric oxide (NO), prostaglandin $\mathrm{E}_{2}\left(\mathrm{PGE}_{2}\right)$ and ROS (22). These factors are involved in pathological conditions of various neurodegenerative diseases, such as AD, PD, MS, trauma and cerebral ischemia $(23,24)$. Thus, reducing pro-inflammatory mediators in microglia may attenuate the severity of neurodegenerative disorders $(25,26)$. Activated microglia are major cellular sources of the pro-inflammatory and/or cytotoxic factors that lead to neuronal damage in the CNS. Among the pro-inflammatory cytokines involved in neuroinflammation, IL-1 $\beta$ results from the inflammasome activation pathway. In this study, we demonstrate the inhibitory effects of BITC on low 
levels of IL-1 $\beta$ production in ultrapure $E$. coli LPS-stimulated BV2 microglia without the addition of extracellular ATP.

LPS induces neuroinflammation by activating inflammatory cells, including astrocytes and microglial cells $(27,28)$. In a previous study, systemically injecting LPS led to neuroinflammatory responses in the brain, leading to amyloid- $\beta$ accumulation $(\mathrm{A} \beta)$, which is toxic to neurons (29). IL-1 $\beta$ is produced in LPS-stimulated BV2 microglia. The present study demonstrated that BITC inhibited IL-1 $\beta$ production in LPS-stimulated BV2 microglia (Fig. 2). The inflammasome is required for IL- $1 \beta$ maturation in LPS-stimulated BV2 microglia. In this regard, we investigated whether BITC inhibits IL-1 $\beta$ expression by suppressing inflammasome activation. The cells were stimulated with LPS followed by the assembly and activation of the inflammasome, which facilitated caspase-1 activation. Without extracellular ATP, the expression of NLRP3 and active caspase-1 markedly increased in response to LPS stimulation; however, treatment with BITC ameliorated this increase in a dose-dependent manner (Fig. 3). Therefore, the regulation of IL-1 $\beta$ production by BITC may be an effective means of inhibiting neuroinflammation through the attenuation of inflammasome activation.

Cell priming with LPS is necessary for ATP binding to surface-expressed $\mathrm{P} 2 \mathrm{X} 7$ purinergic receptors (P2X7Rs), which are ATP-gated non-selective cation channels, to induce inflammasome activation, which results in IL-1 $\beta$ secretion (30). A recent study showed that $\mathrm{P} 2 \mathrm{X} 7 \mathrm{Rs}$ contribute to various CNS pathologies (31). ATP, a damage associated molecular pattern, is released by any type of cell injury. ATP binding to P2X7R facilitates $\mathrm{K}^{+}$efflux, which then activates the NLRP3 inflammasome (32). To determine whether BITC inhibits IL-1 $\beta$ production by altering ATP secretion, we measured the levels of secreted ATP in LPS-stimulated BV2 microglia. BITC dereased ATP secretion in a concentration-dependent manner (Fig. 4).

Although certain scholars debate this point, the field generally accepts the in vitro macrophage studies indicating that the activation and release of IL-1 $\beta$ via an NLRP3inflammasome-dependent response requires two distinct signals: i) first, a priming signal can be triggered by pathogenassociated molecular pattern (PAMP) molecules, such as LPS, that target toll-like receptors and NF- $\mathrm{B}$, which leads to pro-IL-1 $\beta$ synthesis; ii) second, a signal can be derived from P2X7R activation, which leads to caspase-1 activation and the release of IL-1 $\beta(33,34)$. Therefore, LPS, the first signal, combined with ATP, the second signal, are commonly used to induce IL-1 $\beta$ production in microphages in vitro. However, LPS stimulation alone upregulated IL-1 $\beta$ production in our in vitro study (Fig. 2). In addition, we found that stimulation with LPS alone induced NLRP3 and caspase-1 activation (Fig. 3). Therefore, we examined whether LPS stimulation alone can induce ATP secretion. Of note, in our in vitro study, LPS stimulation alone significantly upregulated ATP secretion (Fig. 4). ATP acted in an autocrine mode when LPS stimulation alone was used for stimulation. Furthermore, while P2X7R did not induce expression with LPS stimulation, at almost basal levels, the BV2 cells constitutively expressed P2X7R (data not shown). However, BITC decreased ATP secretion in a concentration-dependent manner in the LPS-stimulated BV2 microglia (Fig. 4).
NLRP3 inflammasome activation has been widely implicated in ROS and NF- $\kappa$ B signaling $(19,35)$. Therefore, NF- $\kappa$ B signaling and ROS levels were examined in this study. It has been proposed that ROS are an actual trigger for NLRP3 inflammasome assembly (36). Furthermore, potassium efflux triggers ROS production in human granulocytes (37). To investigate whether ROS production was responsible for the enhanced IL-1 $\beta$ production, we stimulated the cells with LPS in the presence of a mitochondrial ROS inhibitor or total ROS scavenger. In the present study, YCG 063, a mitochondrial ROS inhibitor, inhibited IL- $1 \beta$ production. However, NAC or DPI did not attenuate ROS production. In previous studies, mitochondrial-derived ROS were shown to be associated with NLRP3 activation (38-40). These data suggest that BITC attenuates NLRP3 activation via mitochondria-generated ROS inhibition. Furthermore, a previous study reported that NF- $\kappa \mathrm{B}$ is involved in IL-1 $\beta$, NLRP3 and caspase-1 expression (41). In previous studies, LPS-induced neuroinflammation was associated with upregulated NF- $\kappa \mathrm{B}$ expression $(42,43)$. Consistent with these studies, we investigated whether the treatment of LPS-stimulated BV2 microglia with BITC inhibits NF- $\kappa \mathrm{B}$ activation. We found that BITC inhibited NF- $\kappa$ B activation. Collectively, based on these previous observations and our results, BITC likely attenuates IL-1 $\beta$ production and NLRP3 inflammasome activation by inhibiting mitochondrial ROS generation and $\mathrm{NF}-\kappa \mathrm{B}$ activation. Our results are consistent with those of previous publications, showing that LPS or $\mathrm{NF}-\kappa \mathrm{B}$ prime NLRP3 complex formation and ROS activate the NLRP3 complex $(19,30,44)$.

In conclusion, our data demonstrate that BITC decreases IL-1 $\beta$ production in activated BV2 microglia. Our data also show that the decreased IL-1 $\beta$ production and the inhibition of NLRP3 inflammasome activation is associated with the attenuation of mitochondrial ROS generation and NF- $\kappa \mathrm{B}$ activation by treatment with BITC. Thus, treatment with BITC may be an effective novel therapeutic strategy with which to combat inflammation-associated pathological damage which occurs due to LPS by targeting inflammasome-mediated signaling pathways. Further studies are warranted however, to determine whether BITC suppresses LPS-induced inflammasome-related neuroinflammation in vivo.

\section{Acknowledgements}

This study was supported by the Basic Science Research program through the National Research Foundation of Korea (NRF) funded by the Ministry of Education, Science and Technology (no. 2013R1A1A4A01011649).

\section{References}

1. Dinarello CA: A clinical perspective of IL-1 $\beta$ as the gatekeeper of inflammation. Eur J Immunol 41: 1203-1217, 2011.

2. Li L, Fei Z, Ren J, Sun R, Liu Z, Sheng Z, Wang L, Sun X, Yu J, Wang Z, et al: Functional imaging of interleukin 1 beta expression in inflammatory process using bioluminescence imaging in transgenic mice. BMC Immunol 9: 49, 2008.

3. Allan SM, Tyrrell PJ and Rothwell NJ: Interleukin-1 and neuronal injury. Nat Rev Immunol 5: 629-640, 2005.

4. Cappellano G, Carecchio M, Fleetwood T, Magistrelli L, Cantello R, Dianzani U and Comi C: Immunity and inflammation in neurodegenerative diseases. Am J Neurodegener Dis 2: 89-107, 2013. 
5. Lu X, Ma L, Ruan L, Kong Y, Mou H, Zhang Z, Wang Z, Wang JM and Le Y: Resveratrol differentially modulates inflammatory responses of microglia and astrocytes. J Neuroinflammation 7: 46, 2010.

6. Sheng JG, Bora SH, Xu G, Borchelt DR, Price DL and Koliatsos VE: Lipopolysaccharide-induced-neuroinflammation increases intracellular accumulation of amyloid precursor protein and amyloid beta peptide in APPswe transgenic mice. Neurobio Dis 14: 133-145, 2003.

7. Cassel SL, Joly S and Sutterwala FS: The NLRP3 inflammasome: A sensor of immune danger signals. Semin Immunol 21: 194-198, 2009.

8. De Nardo D and Latz E: NLRP3 inflammasomes link inflammation and metabolic disease. Trends Immunol 32: 373-379, 2011

9. Englezou PC, Rothwell SW, Ainscough JS, Brough D, Landsiedel R, Verkhratsky A, Kimber I and Dearman RJ: P2X7R activation drives distinct IL-1 responses in dendritic cells compared to macrophages. Cytokine 74: 293-304, 2015.

10. Mariathasan S, Weiss DS, Newton K, McBride J, O'Rourke K, Roose-Girma M, Lee WP, Weinrauch Y, Monack DM and Dixit VM: Cryopyrin activates the inflammasome in response to toxins and ATP. Nature 440: 228-232, 2006.

11. Schroder K, Zhou R and Tschopp J: The NLRP3 inflammasome: A sensor for metabolic danger? Science 327: 296-300, 2010.

12. Ferrari D, Pizzirani C, Adinolfi E, Lemoli RM, Curti A, Idzko M, Panther E and Di Virgilio F: The P2X7 receptor: A key player in IL-1 processing and release. J Immunol 176: 3877-3883, 2006.

13. Lam TK, Gallicchio L, Lindsley K, Shiels M, Hammond E, Tao XG, Chen L, Robinson KA, Caulfield LE, Herman JG, et al: Cruciferous vegetable consumption and lung cancer risk: A systematic review. Cancer Epidemiol Biomarkers Prev 18: 184-195, 2009.

14. Tang L, Paonessa JD, Zhang Y, Ambrosone CB and McCann SE: Total isothiocyanate yield from raw cruciferous vegetables commonly consumed in the United States. J Funct Foods 5: 1996-2001, 2013.

15. Wu X, Zhou QH and Xu K: Are isothiocyanates potential anticancer drugs? Acta Pharmacol Sin 30: 501-512, 2009.

16. Lee Y, Kim YJ, Choi YJ, Lee JW, Lee S and Chung HW: Enhancement of cisplatin cytotoxicity by benzyl isothiocyanate in HL-60 cells. Food Chem Toxicol 50: 2397-2406, 2012.

17. Lai KC, Huang AC, Hsu SC, Kuo CL, Yang JS, Wu SH and Chung JG: Benzyl isothiocyanate (BITC) inhibits migration and invasion of human colon cancer HT29 cells by inhibiting matrix metalloproteinase-2/-9 and urokinase plasminogen (uPA) through PKC and MAPK signaling pathway. J Agric Food Chem 58: 2935-2942, 2010.

18. Lee YM, Seon MR, Cho HJ, Kim JS and Park JH: Benzyl isothiocyanate exhibits anti-inflammatory effects in murine macrophages and in mouse skin. J Mol Med Berl 87: 1251-1261, 2009.

19. Bauernfeind FG, Horvath G, Stutz A, Alnemri ES, MacDonald K, Speert D, Fernandes-Alnemri T, Wu J, Monks BG, Fitzgerald KA, et al: Cutting edge: NF-kappaB activating pattern recognition and cytokine receptors license NLRP3 inflammasome activation by regulating NLRP3 expression. J Immunol 183: 787-791, 2009.

20. Hagberg H, Mallard C, Ferriero DM, Vannucci SJ, Levison SW Vexler ZS and Gressens P: The role of inflammation in perinatal brain injury. Nat Rev Neurol 11: 192-208, 2015.

21. de Rivero Vaccari JP, Dietrich WD and Keane RW: Therapeutics targeting the inflammasome after central nervous system injury. Transl Res 167: 35-45, 2016.

22. Jung WK, Lee DY, Park C, Choi YH, Choi I, Park SG, Seo SK, Lee SW, Yea SS, Ahn SC, et al: Cilostazol is anti-inflammatory in BV2 microglial cells by inactivating nuclear factor-kappaB and inhibiting mitogen-activated protein kinases. Br J Pharmacol 159: 1274-1285, 2010.

23. McGeer PL and McGeer EG: The inflammatory response system of brain: Implications for therapy of Alzheimer and other neurodegenerative diseases. Brain Res Brain Res Rev 21: 195-218, 1995.
24. González-Scarano F and Baltuch G: Microglia as mediators of inflammatory and degenerative diseases. Annu Rev Neurosci 22: 219-240, 1999.

25. Liu B and Hong JS: Role of microglia in inflammation-mediated neurodegenerative diseases: Mechanisms and strategies for therapeutic intervention. J Pharmacol Exp Ther 304: 1-7, 2003.

26. Eikelenboom P and van Gool WA: Neuroinflammatory perspectives on the two faces of Alzheimer's disease. J Neural Transm Vienna 111: 281-294, 2004.

27. Pascual-Lucas M, Fernandez-Lizarbe $\mathbf{S}$, Montesinos $\mathbf{J}$ and Guerri C: LPS or ethanol triggers clathrin- and rafts/caveolaedependent endocytosis of TLR4 in cortical astrocytes. J Neurochem 129: 448-462, 2014.

28. Min KJ, Choi K and Kwon TK: Withaferin A down-regulates lipopolysaccharide-induced cyclooxygenase-2 expression and $\mathrm{PGE}_{2}$ production through the inhibition of STAT1/3 activation in microglial cells. Int Immunopharmacol 11: 1137-1142, 2011.

29. Lull ME and Block ML: Microglial activation and chronic neurodegeneration. Neurotherapeutics 7: 354-365, 2010.

30. Franchi L, Eigenbrod T and Núñez G: Cutting edge: TNF-alpha mediates sensitization to ATP and silica via the NLRP3 inflammasome in the absence of microbial stimulation. J Immunol 183: 792-796, 2009.

31. Sperlágh B and Illes P: P2X7 receptor: An emerging target in central nervous system diseases. Trends Pharmacol Sci 35: 537-547, 2014.

32. Choi AJ and Ryter SW: Inflammasomes: Molecular regulation and implications for metabolic and cognitive diseases. Mol Cells 37: 441-448, 2014.

33. Mariathasan S and Monack DM: Inflammasome adaptors and sensors: Intracellular regulators of infection and inflammation. Nat Rev Immunol 7: 31-40, 2007.

34. Guo H, Callaway JB and Ting JP: Inflammasomes: Mechanism of action, role in disease, and therapeutics. Nat Med 21: 677-687, 2015.

35. Martinon F: Signaling by ROS drives inflammasome activation. Eur J Immunol 40: 616-619, 2010.

36. Tschopp J and Schroder K: NLRP3 inflammasome activation: The convergence of multiple signalling pathways on ROS production? Nat Rev Immunol 10: 210-215, 2010.

37. Fay AJ, Qian X, Jan YN and Jan LY: SK channels mediate NADPH oxidase-independent reactive oxygen species production and apoptosis in granulocytes. Proc Natl Acad Sci USA 103: 17548-17553, 2006.

38. Zhou R, Yazdi AS, Menu P and Tschopp J: A role for mitochondria in NLRP3 inflammasome activation. Nature 469: 221-225, 2011.

39. Wen H, Gris D, Lei Y, Jha S, Zhang L, Huang MT, Brickey WJ and Ting JP: Fatty acid-induced NLRP3-ASC inflammasome activation interferes with insulin signaling. Nat Immunol 12: 408-415, 2011.

40. Nakahira K, Haspel JA, Rathinam VA, Lee SJ, Dolinay T, Lam HC, Englert JA, Rabinovitch M, Cernadas M, Kim HP, et al: Autophagy proteins regulate innate immune responses by inhibiting the release of mitochondrial DNA mediated by the NALP3 inflammasome. Nat Immunol 12: 222-230, 2011.

41. Budai MM, Varga A, Milesz S, Tőzsér J and Benkő S: Aloe vera downregulates LPS-induced inflammatory cytokine production and expression of NLRP3 inflammasome in human macrophages. Mol Immunol 56: 471-479, 2013.

42. Zhang F, Qian L, Flood PM, Shi JS, Hong JS and Gao HM: Inhibition of IkappaB kinase-beta protects dopamine neurons against lipopolysaccharide-induced neurotoxicity. J Pharmacol Exp Ther 333: 822-833, 2010.

43. Hang CH, Shi JX, Tian J, Li JS, Wu W and Yin HX: Effect of systemic LPS injection on cortical NF-kappaB activity and inflammatory response following traumatic brain injury in rats. Brain Res 1026: 23-32, 2004.

44. Land WG: Transfusion-related acute lung injury: The work of DAMPs. Transfus Med Hemother 40: 3-13, 2013. 